\title{
USO DE METODOLOGIAS ALTERNATIVAS NO ENSINO DE CIÊNCIAS: UM ESTUDO REALIZADO COM O CONTEÚDO DE SERPENTES
}

\section{USE OF ALTERNATIVE METHODOLOGIES IN THE SCIENCE TEACHING: A STUDY OF THE CONTENTES OF SNAKES}

\author{
Lais de Souza Bernardes ${ }^{1}$, Larissa Palhano Soares ${ }^{2}$, Nayara Miranda Lio dos Santos, \\ Fernanda de Jesus Costa ${ }^{4}$, Camila Guimarães Torquetti ${ }^{5}$ \\ ${ }^{1}$ Licenciada em Ciências Biológicas/laisbernardes11@gmail.com \\ ${ }^{2}$ Licenciada em Ciências Biológicas/larissapalhano@hotmail.com \\ ${ }^{3}$ Licenciada em Ciências Biológicas/ lio.nayara@gmai.com \\ ${ }^{4}$ Universidade do Estado de Minas Gerais/Departamento de Ciências Biológicas/fernanda.costa@uemg.br \\ ${ }^{5}$ Universidade Federal de Minas Gerais/Programa de Pós Graduação em Ciência \\ Animal/camilatorquetti@gmail.com
}

\begin{abstract}
RESUMO
As serpentes são animais que apesar de serem importantes sob o ponto de vista ecológico, social e da saúde pública, têm sofrido constantes ataques e perseguições em decorrência do medo e desconhecimento da população. Este trabalho teve como objetivo verificar a eficácia de uma metodologia alternativa no ensino de serpentes para alunos do ensino fundamental de uma Escola Estadual da região metropolitana de Belo Horizonte, Minas Gerais. Foram aplicados dois questionários para verificação do conhecimento, um antes e outro após a intervenção, que consistiu em uma palestra com exposição de serpentes vivas. O pré-questionário evidenciou a presença de equívocos e mitos relacionados às serpentes, e no pós-questionário observou-se uma melhora na compreensão dos assuntos trabalhados. A metodologia alternativa se mostrou eficiente no sentido de despertar a curiosidade dos alunos, bem como alternativa capaz de facilitar a aquisição do conhecimento. Desta forma, pode-se inferir que metodologias alternativas são ferramentas necessárias para o ensino de Ciências e cada vez mais os professores devem utilizar estes recursos.
\end{abstract}

Palavras-chave: Metodologias Alternativas, ensino de serpentes, processos de ensino e de aprendizagem

\begin{abstract}
Snakes are animals that although they are important from the point of ecological, social order and public health, have suffered constant attacks and persecutions as a consequence of fear and the population's lack of knowledge. This study aimed to verify the effectiveness of an alternative methodology to elementary school students in snake teaching in a state school in the metropolitan area of Belo Horizonte, Minas Gerais. Two questionnaires for knowledge assessment were applied, one before and the other after the intervention. They consisted of a lecture with the presence of live snakes. The pre-questionnaire showed the presence of misconceptions and myths related to snake, and the post-questionnaire showed an improvement in the understanding of issues that were worked out with the students. The alternative methodology proved its efficiency in stimulating the curiosity of students as well as enabling and facilitating their acquisition of knowledge. This way, we can conclude that alternative methodologies are necessary tools for teaching science and teachers should use such resources increasingly.
\end{abstract}

Key words: Alternative Methodologies, teaching snakes, processes of teaching and learning 
Ensino, Saúde e Ambiente - V9 (1), pp. 63-76, Abril, 2016.

\section{INTRODUÇÃO}

O ensino de Ciências caracteriza-se por ser atraente, estimulante e necessário tanto no contexto escolar quanto no social. Para que isto aconteça é importante que o professor realize seu papel de forma consciente e que os alunos estejam realmente interessados na aprendizagem destes conteúdos. Isto não é uma tarefa simples no ambiente escolar, nem para o aluno, muito menos para o professor. Muitas vezes, é preciso que o professor utilize diferentes ferramentas com o objetivo de favorecer a aprendizagem.

Alguns conteúdos de Ciências e Biologia apresentam certa dificuldade nos processos de ensino e de aprendizagem, neste contexto destaca-se o ensino de zoologia, e mais especificamente o de serpentes. Embora o tema seja pouco explorado em sala de aula, é recebido pelos alunos com grande curiosidade uma vez que é cercado de misticismo (CARVALHO, BRAGA, 2013). Este é um conteúdo extremamente importante, já que as serpentes apresentam importância social, cultural, ecológica e ainda na saúde pública.

O Brasil é um dos países mais ricos em espécies de serpentes, abrigando aproximadamente 386 espécies, das quais 55 são peçonhentas (BÉRNILS, COSTA, 2012). Sendo assim, apenas $14 \%$ das serpentes que ocorrem em território nacional produzem veneno e possuem mecanismo para sua inoculação.

As serpentes, de um modo geral, despertam medo, curiosidade e fascínio nas pessoas. A presença desses animais em histórias folclóricas, provérbio e mitos que são transmitidos ao longo das gerações fortalece a ideia de serem animais perigosos (ANDREU, 2000; FERNANDES-FERREIRA et al., 2011; ALVES et al., 2014). E dessa forma, o grupo tem sofrido constantes ataques e perseguições em decorrência do medo e desconhecimento da população (BARRAVIEIRA, PERAÇOLI, 1999; ALVES et al., 2014).

Apesar de serem conhecidos apenas como animais perigosos devido aos casos de acidentes ofídicos, as serpentes são importantes na manutenção do equilíbrio na cadeia trófica (ZUG et al., 2001). Além disso, o veneno produzido por elas tem sido bastante estudado devido o seu elevado potencial farmacológico (HESS, SQUAIELLABAPTISTÃO, 2012). 


\section{Ensino, Saúde e Ambiente - V9 (1), pp. 63-76, Abril, 2016.}

Devido a esta importância é preciso pensar neste conteúdo no ambiente escolar e assim, propor novas metodologias para o ensino de serpentes. É importante destacar que o professor deve estimular a aprendizagem dos alunos, sendo o responsável pela dinâmica do processo de aprendizagem. O professor deve propor novas formas de ensinar favorecendo a participação e o interesse dos alunos. O ensino de serpentes encontra-se na disciplina de Ciências e na maioria das vezes o único material que o professor possui são os livros didáticos, os quais frequentemente apresentam erros conceituais relacionados a serpentes e aos acidentes ofídicos (SANDRIN, PUORTO, NARDI, 2006).

Este aspecto dificulta ainda mais o ensino e a aprendizagem deste conteúdo, fazendo-se necessário a introdução de novas metodologias para o ensino de serpentes. Existem diferentes metodologias que podem ser aplicadas ao ensino de Ciências e Biologia, destacando-se palestras, aulas expositivas, jogos, entre outros (KRASILCHIK, 2008).

Acredita-se que o ensino de Ciências deve ser ativo, crítico, atualizado e com metodologias alternativas, favorecendo os processos de ensino e aprendizagem. Nesse contexto, Aguiar (1998) afirma que a base do construtivismo é a interação progressiva do mesmo com o meio e não diretamente do objeto. Sendo assim, no ensino de Ciências é de grande importância que o indivíduo consiga relacionar o objeto de estudo com aspectos cotidianos para assimilar o conhecimento. Com isso o aluno não deve apenas aprender o conteúdo científico, mas sim desenvolver seu pensamento crítico (capacidade de compreender, examinar argumentos, hipóteses e teorias) e objetividade sobre os temas estudados e incorporá-los em sua vida.

O ensino desta disciplina deve ir além de uma aprendizagem voltada aos conteúdos fundamentais, deve contribuir para uma aprendizagem sobre o conteúdo em geral e voltada para a compreensão do todo (AGUIAR, 1998), relacionando com o ambiente no qual o aluno está inserido.

É importante destacar que o aluno é um sujeito ativo e tem grande participação na construção do conhecimento científico, o qual deve ir além do conteúdo visto em sala (AGUIAR, 1998). As aulas de Ciências apresentam como objetivo a preparação do aluno para o exercício da cidadania, ou seja, deve trabalhar conteúdos científicos no contexto educacional e que estes sejam aplicados no cotidiano do aluno (SANTOS, MORTIMER, 2002). É preciso que o conhecimento da sala de aula seja utilizado também fora da escola. 


\section{Ensino, Saúde e Ambiente - V9 (1), pp. 63-76, Abril, 2016.}

Assim, tornam-se necessárias as relações entre o conhecimento de dentro e fora do universo escolar, favorecendo assim, questionamentos sobre situações cotidianas (UHMANN, ZANNON, 2013). Desta forma, acredita-se que a construção do conhecimento é favorecida pelo diálogo e união dos conhecimentos culturais e sociais com o científico.

É importante que o conteúdo aprendido no ambiente escolar seja aplicado fora da escola, em relação ao conhecimento sobre serpentes isto é muito interessante, já que as pessoas tendem a matar as serpentes sem conhecimento destes indivíduos para o ecossistema.

Seguindo este raciocínio e acompanhando o processo escolar, as intervenções pedagógicas precisam ser atualizadas, fazendo-se necessária sempre seu aperfeiçoamento para favorecer o ensino e relacionar questões teórico/práticas e socioambientais (UHMANN, ZANNON, 2013). É preciso que o ensino sobre serpentes seja capaz de articular o conhecimento científico com o cotidiano dos alunos, estimulando o conhecimento prévio dos alunos, bem como suas experiências.

Através das atividades práticas o aluno pode chegar a suas próprias conclusões sobre o assunto abordado (VASCONCELOS, SOUTO, 2003). Ao realizar estas atividades o aluno torna-se ativo, ao construir um conhecimento científico, baseando-se assim no construtivismo. Portanto, o ensino não deve ficar restrito apenas a aulas expositivas. É preciso ir além deste tradicionalismo imposto, o professor deve ser capaz de propor novas maneiras de inserir o conteúdo na sala de aula, uma maneira é através de atividades práticas, as quais podem ser definidas como atividades em que o aluno pode entrar em contato com a teoria de forma mais aplicada e mais prática. Não está necessariamente relacionada com a aula realizada dentro de um laboratório, pode ser entendida como um trabalho de campo, uma atividade com exemplares vivos, uma atividade com o computador, entre outras atividades.

A maioria dos docentes reconhece que a aula prática, a atividade experimental, aula de laboratório e de campo são estratégias que podem ser funcionais e importantes para o aprendizado de conteúdos científicos. Apesar disso, grande parte desses docentes não utiliza estas metodologias em suas aulas, utilizando principalmente aulas expositivas, o que pode proporcionar uma aprendizagem incompleta, já que na maioria das vezes não ocorre um envolvimento ativo dos alunos (BEREZUCK, OBARA, SILVA, 2009). É preciso que o aluno seja ativo na construção do seu conhecimento. Neste sentido, "o trabalho prático consiste em atividades em que os alunos praticam no 
Ensino, Saúde e Ambiente - V9 (1), pp. 63-76, Abril, 2016.

domínio psicomotor, cognitivo e afetivo" (BEREZUCK, OBARA, SILVA, 2009), relaciona-se muitas vezes com atividades através das quais o aluno pode ter contato direto com a natureza.

O contato com a natureza proporciona aos estudantes uma experiência direta e a utilização deste fator para uma maior conscientização ambiental, tornando possível assim adoção de atitudes sustentáveis (DOURADO, 2006).

Além do trabalho realizado fora do ambiente escolar, o professor pode e deve propor novas formas de trabalhar o conteúdo didático dentro da sala de aula. Uma palestra contendo animais vivos, na quais é possível compreender um pouco mais desta temática, pode ser compreendida como uma metodologia alternativa. Neste sentido, é importante ressaltar que o contato com a natureza gera resultados positivos na aprendizagem (SENICIATO, CAVASSAN, 2004).

Diversas pesquisas no ensino de Ciências vêm destacando a utilização de metodologias alternativas e pode-se destacar uma intervenção realizada no ensino de bioquímica, com alunos da $7^{\mathrm{a}}$ série que gerou resultados positivos, demonstrando que a necessidade de o professor utilizar ferramentas alternativas para favorecer a aprendizagem (SANTOS et al, 2012).

Em relação ao ensino de serpentes, merece destaque o trabalho realizado com jogos para o ensino deste conteúdo que também alcançou resultados positivos na aprendizagem e interesse dos alunos (CARVALHO, BRAGA, 2013).

Estes exemplos demonstram que novas ferramentas são capazes de favorecer a aquisição de conhecimentos, gerando interesse nos alunos pelo que está sendo ensinado e ainda estímulo para o professor continuar trabalhando. O professor deve utilizar diferentes metodologias com o intuito de favorecer a aprendizagem.

Considerando a presença marcante de mitos e preconceitos que envolvem as serpentes e a necessidade de implementar medidas de educação ambiental a fim de esclarecer as pessoas acerca da importância desses animais nos ecossistemas e na saúde pública, este trabalho teve como objetivo avaliar uma metodologia alternativa no ensino de serpentes para alunos do ensino fundamental.

\section{MATERIAIS E MÉTODOS}

O presente trabalho foi desenvolvido em uma Escola Estadual localizada no Município de Ibirité, Minas Gerais. Foram selecionados 130 alunos do $8^{\circ}$ ano do ensino 


\section{Ensino, Saúde e Ambiente - V9 (1), pp. 63-76, Abril, 2016.}

fundamental, por estarem familiarizados com o conteúdo de serpentes, já que este foi ministrado no $7^{\circ}$ ano. Esses alunos tinham em média 14 anos de idade.

Um questionário prévio foi elaborado para verificar os possíveis problemas no processo de aprendizagem do conteúdo como erros de identificação, caracterização inadequada de serpentes brasileiras e presença de mitos sobre o assunto. As informações obtidas com o questionário foram importantes para orientar a elaboração da palestra.

De posse das informações obtidas com o questionário foi realizada uma intervenção com os alunos nas dependências da Universidade do Estado de Minas Gerais - Unidade Ibirité. Esta etapa contou com a colaboração de um sargento militar reformado que realiza trabalhos de educação ambiental com serpentes. Uma palestra foi ministrada com o auxílio de um projetor multimídia para a exibição de imagens e informações complementares. Dos tópicos abordados merecem destaque: 1) a importância dos animais e sua relação com o homem; 2) a evolução com foco nas serpentes; 3 ) características gerais das serpentes brasileiras, como foco na diferenciação de serpentes peçonhentas e não peçonhentas, por exemplo, diferenciar a coral verdadeira (Micrurus sp.) da falsa coral, dentições das serpentes, quais as atitudes a serem tomadas em um encontro repentino com serpentes; 4) como proceder em caso de acidentes com ofídios, e por fim; 5) esclarecimentos sobre mitos e curiosidades.

Após a palestra, os profissionais realizaram a exposição das serpentes peçonhentas vivas, como a cascavel (Crotalus durissus) e jararaca (Bothrops sp.) e nãopeçonhentas como a falsa coral (Oxyrhopus sp.) e jibóia (Boa constrictor). Essa exposição teve como objetivo promover o contato dos alunos com as serpentes o qual é importante para minimizar a aversão dos alunos por esses animais. Posteriormente, abriu-se um tempo para perguntas para que os alunos esclarecessem suas dúvidas sobre o tema.

Ao término da intervenção, foi aplicado um questionário semelhante ao anterior para reavaliar o conhecimento e verificar a percepção dos alunos sobre serpentes após a intervenção. Os dados obtidos através de ambos os questionários foram analisados quali-quatitativamente.

\section{RESULTADO E DISCUSSÃO}

A primeira questão tinha como objetivo verificar se os alunos eram capazes de reconhecer as características de uma serpente peçonhenta. Se estes conseguiam 


\section{Ensino, Saúde e Ambiente - V9 (1), pp. 63-76, Abril, 2016.}

diferenciar animais venenosos de peçonhentos. No questionário aplicado antes da intervenção, verificou-se que 36,92\% dos alunos responderam corretamente, "possui veneno e mecanismos de inoculá-lo". O restante dos alunos se dividiu entre as seguintes alternativas: 25,38\% "Que possui veneno e a glândula excretora"; 20\% "Possui veneno e cabeça triangular"; 15,38\% "Possui veneno e dentição áglifa" e 2,3\% não responderam. Assim, verifica-se que estes conceitos não são totalmente claros para os alunos.

Segundo Melgarejo-Giménez (2002) somente as serpentes com mecanismo de inoculação do veneno são consideradas peçonhentas, aquelas serpentes que produzem veneno, mas não possuem mecanismo para inoculá-lo não são consideradas peçonhentas. Nesta questão verificou-se um percentual baixo de alunos que conseguiram fazer esta diferenciação (36,92\%). Após a realização da intervenção, houve um aumento do número de acertos desta questão $(52,8 \%)$.

Esta melhoria pode ser explicada devido à intervenção realizada já que através da atividade desenvolvida os alunos puderam compreender mais sobre serpentes, esclarecer dúvidas e ainda ter contato tátil e visual com estes animais. Assim, concordase com Dourado (2006) quando afirma que o contato com a natureza através do trabalho de campo proporciona aos estudantes uma experiência direta e a utilização deste fator é importante para uma maior conscientização ambiental.

Assim, a palestra usando os animais vivos, foi um trabalho de campo que produziu bons resultados para o ensino de serpentes dos alunos participantes desta pesquisa. Estes resultados encontrados são semelhantes aos encontrados em outros trabalhos nos quais foram utilizadas metodologias diferenciadas (CARVALHO, BRAGA, 2013; SANTOS, et al., 2012). Assim, verifica-se a necessidade da inserção destas no ensino de Ciências e Biologia.

Ainda dentro desta perspectiva, na segunda questão (questão aberta), foi solicitado aos alunos que escrevessem as características de serpentes peçonhentas. Como resposta correta foi considerada a presença do mecanismo de inoculação de veneno e fosseta loreal (MELGAREJO-GIMÉNEZ, 2002). No pré-questionário um pequeno percentual $(36,92 \%)$ respondeu corretamente: "Possuem fosseta loreal e mecanismo para inocular o veneno", a grande maioria respondeu incorretamente $(60,76 \%)$ e o restante não respondeu ou afirmou não saber (2,32\%). É importante destacar que aqueles alunos que responderam incorretamente relacionavam suas explicações aos erros conceituais comuns em diversos livros didáticos, tais como 
Ensino, Saúde e Ambiente - V9 (1), pp. 63-76, Abril, 2016.

"cabeça triangular e ou cauda que afina abruptamente" (SANDRIN, PUORTO, NARDI, 2006).

Após a realização da intervenção pode-se identificar uma melhora no percentual de acertos dos alunos (56,8\%), porém ainda assim o número de respostas incorretas se manteve praticamente inalterado. Isto pode ser explicado devido ao fato de conhecimentos populares, mitos e erros conceituais estarem enraizados nos alunos, o que dificulta a aquisição de conhecimentos científicos.

Apesar do percentual de acertos ter aumentado pouco, pode-se afirmar que a realização da atividade foi capaz de melhorar os conhecimentos dos alunos, já que aqueles que não sabiam, já foram capazes de responder. Resultados semelhantes foram encontrados em pesquisas que realizaram intervenções no ensino de ciências (SILVA et al., 2012).

É preciso considerar a dificuldade que os alunos encontram em aceitar o conhecimento científico em detrimento do conhecimento cultural já adquirido (MORTIMER, 1996). Frequentemente, esse conhecimento científico é aplicado somente na prova sendo esquecido posteriormente. É necessário que o professor utilize novas ferramentas com o objeto de favorecer a verdadeira aquisição de conhecimentos científicos.

Com o objetivo de relacionar o ensino de serpentes com os mitos, na questão 3, perguntou-se qual a função do chocalho da cascavel? No questionário realizado antes da intervenção, verificou-se que 54,61\% dos alunos responderam corretamente "Defesa", pois o animal ao pressentir perigo balança o guizo para avisar que está no ambiente e que para se defender dará o bote. O restante dos alunos se dividiu entre as seguintes alternativas: 13,84\% "Para mostrar sua idade", 10,76\% "Chamar a atenção da fêmea para a cópula", $18,46 \%$ "Como comunicação" e 2,3\% não responderam. Dessa forma, observou-se que $43,09 \%$ dos alunos possuíam mitos e conceitos equivocados sobre o guizo.

Após a realização da atividade de intervenção, pode se identificar uma mudança relevante no percentual de acertos, o qual aumentou de 54,61\% para 90,4\%. As explicações referentes ao chocalho da cascavel produziram resultados positivos na mudança de conceito dos alunos.

A função do chocalho da cascavel é um tema que desperta interesse nos alunos, por estar relacionado com aspectos culturais, sendo assim, concorda-se com Santos et al (2012), que o conteúdo deve relacionar com aspectos sociais e culturais dos alunos, 


\section{Ensino, Saúde e Ambiente - V9 (1), pp. 63-76, Abril, 2016.}

favorecendo assim a aprendizagem. Desta forma, pode-se concluir que esta proximidade pode contribuir para a aquisição deste conhecimento. O professor de Ciências deve aproximar o conteúdo científico da realidade dos alunos favorecendo o interesse, participação e construção do conhecimento dos mesmos.

A questão seguinte pretendia verificar se os alunos eram capazes de diferenciar a coral verdadeira da falsa, e a partir disso, verificar a ocorrência de equívocos relacionados com essa diferenciação. No pré-questionário, 10,77\% responderam corretamente: "Pelos olhos, anel tríade, pela sua cauda e dentição". O restante dos alunos se dividiu em $60 \%$ incorretas, $29,23 \%$ não responderam. O erro mais frequente diz respeito à identificação através das cores da serpente. Segundo Funed (2014), as serpentes corais (verdadeira ou falsa) possuem diâmetro ocular menor e cauda proporcional ao corpo, dentição proteróglifa (localizada na parte anterior da boca), a qual possui um sulco profundo através do qual o veneno penetra no local da picada do animal.

Após a aplicação da palestra, pode-se identificar uma mudança em relação ao número de acertos dos alunos. Houve um aumento de $10,77 \%$ para $64 \%$, e o restante dos alunos se dividiu em: 27,2\% responderam de forma incorreta, 8,8\% não responderam. Acredita-se que a mudança ocorrida pode ser um resultado da atividade prática. A maioria dos docentes reconhece que a aula prática, experimental, de laboratório e de campo são estratégias que podem ser funcionais e importantes para o aprendizado de conteúdos científicos (BEREZUCK, OBARA, SILVA, 2009). Além disso, neste tipo de atividade, na qual o aluno pode manipular os animais, verifica-se a manifestação de emoções e sensações as quais favorecem a aquisição do conhecimento científico (SENICIATO, CAVASSAN, 2004).

Em seguida, questionou-se sobre a importância das serpentes, com o objetivo de verificar o conhecimento dos alunos sobre a importância ambiental e científica destes animais. No pré-questionário $51,53 \%$ responderam corretamente, citando sua importância ecológica $(26,92 \%)$ ou importância médica $(24,61 \%)$. O restante dos alunos ou não souberam responder ou consideraram que não há nenhuma importância.

As serpentes se alimentam de uma grande variedade de animais atuando como importantes controladoras de populações no ecossistema em que estão inseridas. Além disso, a composição de suas toxinas vem sendo investigada devido o seu potencial farmacológico (FERREIRA, 1965; PEICHOTO et al., 2011; HESS, SQUAIELLABAPTISTÃO, 2012). Após a aplicação da atividade, o número de acertos aumentou de 


\section{Ensino, Saúde e Ambiente - V9 (1), pp. 63-76, Abril, 2016.}

$51,53 \%$ para 82,4\%, dos quais 16,8\% citaram importância ecológica e 65,6\% a importância médica. Embora o número de acertos tenha aumentado, nota-se uma diminuição no número de alunos que consideraram a importância ecológica. Esse resultado mostra que os alunos assimilaram melhor a importância médica, possivelmente por ser de aplicação prática na vida da população e representar uma "utilidade" desses animais (SERPELL, 2004).

O restante dos alunos se dividiu em: 7,2\% responderam de forma incorreta, $10,4 \%$ não souberam responder. Desta forma, pode-se verificar novamente que as Metodologias Alternativas favorecem a aquisição de novos conhecimentos. O professor deve utilizar diferentes ferramentas, como o jogo aplicado ao ensino de serpentes demonstrado por Carvalho e Braga (2013).

$\mathrm{Na}$ pergunta referente aos procedimentos para evitar acidentes com serpentes peçonhentas, 40,76\% responderam corretamente citando medidas tais como não andar descalço ao caminhar na mata ou plantações, usar botas que protejam até os joelhos, não colocar a mão em buracos e não manipular serpentes (FUNED, 2014). Do restante dos alunos 30\% responderam incorretamente, 26,94\% não responderam, 2,3\% deram respostas parcialmente corretas. Após a intervenção, verificou-se um aumento no número de acertos de 40,76\% para $63,2 \%$ e redução no número de respostas incorretas de $30 \%$ para $4,8 \%$, o restante dos alunos (32\%) não respondeu.

Ainda nesta questão, questionou-se quais medidas devem ser tomadas em caso de acidentes ofídicos. Verificou-se que 49,24\% responderam corretamente, 21,53\% responderam incorretamente, 29,23\% não souberam responder. De acordo com as orientações da Fundação Ezequiel Dias não se deve fazer torniquetes, atendimentos caseiros nem cortar ou perfurar o local da picada. É de extrema importância que o indivíduo acidentado procure um posto médico imediatamente para que seja tratado com soro antiofídico (FUNED, 2014). No pós-questionário, também se constatou aumento no número de respostas corretas de $49,24 \%$ para $67,70 \%$ e diminuição no número de respostas incorretas de $21,53 \%$ para $4,8 \%$. Os demais alunos que representam 27,50\% não responderam. Em ambas as questões, houve aumento do número de alunos que não responderam isso pode ocorrer devido à falta de interesse em responder o pós-questionário.

Finalizando o pré questionário, foi solicitado aos alunos que relatassem uma história sobre serpentes. Verificou-se que um alto percentual $(81,54 \%)$ afirmou nunca ter escutado uma história sobre serpentes, já 10,77\% dos alunos que relataram histórias 


\section{Ensino, Saúde e Ambiente - V9 (1), pp. 63-76, Abril, 2016.}

que são consideradas mitos, o restante 6,15\% narraram fatos verídicos de encontros com serpentes e 1,54\% não responderam. As interpretações sobre estes animais são as mais variadas e aparentemente são um misto entre realidade e fantasia, ou até mesmo algo sobrenatural. Muitas respostas dadas pelos alunos encontram-se neste misto de elementos associados com religiosidade, misticismo e crenças populares.

Pode-se destacar a seguinte resposta, "Que uma cobra engoliu dois homens (M. F. C.; aluno da $8^{\text {a }}$ série Escola Sandoval)", "Ela marcou uma pessoa, e todo dia esperava a pessoa na mesma hora e mesmo lugar até dar o bote (A. D. X. G.; aluno da $8^{\text {a }}$ série da Escola Sandoval), "Chocalho da cascavel cura mau olhado" (J. S, aluno da $8^{a}$ série da Escola Sandoval)". Através destas respostas, é possível verificar como estes mitos ainda estão presentes no imaginário popular.

Ao final do pós-questionário, solicitou-se aos alunos que avaliassem a atividade realizada, 87,2\% classificaram a atividade como "Ótima", 12\% como "Boa", 0,8\% como "Regular" e 0\% como "Ruim". Desta forma, verificou-se que a atividade foi bem avaliada pelos alunos e que alcançou bons resultados.

Sendo assim, pode-se inferir que estas atividades são relevantes para os alunos, "O trabalho prático consiste em atividades em que os alunos praticam no domínio psicomotor, cognitivo e afetivo" (BEREZUCK, OBARA, SILVA, 2009), sendo uma das formas de abordagem mais significativa do trabalho prático o trabalho de campo, e ou espaços não formais de ensino, ou seja, perante avaliação dos alunos e resultados obtidos dos questionários analisamos proveitosamente a palestra ministrada como fonte alternativa de construção do conhecimento científico.

\section{CONSIDERAÇÕES FINAIS}

O ensino de serpentes necessita de uma maior atenção por parte dos professores, pois o livro didático, ainda hoje, é deficiente neste assunto e, além disso, é um conteúdo extremamente importante para os alunos, seja do ponto de vista biológico ou social. As serpentes são importantes na manutenção do equilíbrio na cadeia trófica e o veneno produzido por várias espécies tem sido bastante estudado devido o seu elevado potencial farmacológico. Por outro lado, esses animais têm sido encarados como sinônimo de perigo em decorrência dos numerosos casos de acidentes ofídicos e também pelo preconceito que é alimentado por histórias folclóricas, mitos e provérbios, nos quais são representados como seres perigosos e traiçoeiros. $\mathrm{O}$ medo associado ao 
Ensino, Saúde e Ambiente - V9 (1), pp. 63-76, Abril, 2016.

desconhecimento coloca as serpentes em risco, uma vez que frequentemente são alvos de perseguição.

Através do pré-questionário, foi observado que muitos alunos traziam como conhecimento noções equivocadas ou mitos em relação às serpentes. Após a intervenção, observou-se que de um modo geral houve uma melhora na compreensão do assunto, representado pelo aumento no percentual de questões respondidas corretamente. A exposição das serpentes vivas despertou grande interesse por parte dos alunos, sendo, portanto uma excelente metodologia para desmistificar este assunto.

Para que ocorra a aprendizagem deste conteúdo é preciso pensar em novas ferramentas, o professor não pode ficar preso apenas nas aulas expositivas tradicionais, as quais muitas vezes provocam certa falta de interesse por parte dos alunos, é preciso inovar. A inovação tem gerando resultados positivos conforme foi apresentado neste trabalho.

\section{REFERÊNCIAS BIBLIOGRÁFICAS}

AGUIAR, O. O papel do construtivismo na pesquisa em ensino de ciências. Investigações em Ensino de Ciências, v. 3, n. 2,107-120, 1988.

ALVES, R.R.N.; SILVA, V.N.; TROVÃO, D.M.B.M.; OLIVEIRA, J.V.; MOURÃO, J.S.; DIAS, T.L.P.; ALVES, A.G.C.; LUCENA, R.F.P.; BARBOZA, R.R.D.; MONTENEGRO, P.F.G.P. VIEIRA, W.L.S. \& SOUTO, W.M.S. Students'attitudes toward and knowledge about snakes in the semiarid region of Northeastern Brazil. Journal of Ethnobiology and Ethnomedicine, v. 10, n. 30, 2014.

ANDREU, G.C. Mytos, leyendas y realidades de los Reptiles de Mexico. Ciencia Ergo Sum v. 7, n. 3, 286-291, 2000.

BARRAVIERA, B. \& PERAÇOLI, M.T.S. Soroterapia heteróloga. In: B. Barraviera (Coord.). Venenos - Aspectos clínicos e terapêuticos dos acidentes por animais peçonhentos. (pp. 361 - 372) Rio de Janeiro: EPUB., 1999.

BEREZUCK, P. A., OBARA, A. T., \& SILVA, E. S. Concepções e práticas de professoras de ciências em relação aos trabalhos: prático, experimental, laboratorial e de campo. In: Encontro Nacional de Pesquisa em Educação em Ciências. Campinas: 2009, Disponível em: http://posgrad.fae.ufmg.br/posgrad/viienpec/pdfs/1675.pdf

BÉRNILS, R.S. \& COSTA, H.C. Brazilian Reptiles - List of species. Sociedade Brasileira de Herpetologia, 2012. Disponível em: < http://www.sbherpetologia.org.br/checklist/repteis.htm>. Acesso em 07 jun., 2014. 
CARVALHO, E.F.F. \& BRAGA, P.E.T. O jogo de tabuleiro como uma estratégia auxiliadora para o ensino de zoologia, com ênfase para as serpentes. Ensino, Saúde e Ambiente, v. 6, n. 3, 202-217, 2013.

DOURADO L. Concepções e práticas dos professores de ciências naturais relativas à implementação integrada do trabalho laboratorial e do trabalho de campo. Revista Eletrônica de Enseñanza de lãs Ciências, v. 5, n. 1, 2006.

FERNANDES-FERREIRA, H.; CRUZ, R.L.; BORGES-NOJOSA, D.M. \& ALVES, R.R.N. Crenças associadas a serpentes no estado do Ceará, Nordeste do Brasil. Sitientibus série Ciências Biológicas, v. 11, n. 2, 153-163, 2011.

FERREIRA, S. H. A bradykinin-potentiating factor (BPF) present in the venom of Bothrops jararaca. British Journal of Pharmacology and Chemotherapy, v. 24, 163169, 1965.

FUNED . Animais peçonhentos. Cotta G.A. (Org.) 5ed. Belo Horizonte, 2014..

HESS P.L. \& SQUAIELLA-BAPTISTÃO C.C. Toxinas animais: Serpentes da família Colubridae e seus venenos. Estudos de Biologia, Ambiente e Diversidade, v. 34, n. 83, 135-142, 2012.

KRASILCHIK, M. Prática de Ensino de Biologia. 6. ed. São Paulo: Edusp, 2008..

MELGAREJO-GIMÉNEZ, A.R. Criação e manejo de serpentes. In: Andrade, A.; Pinto, S.C.; Oliveira, R.S. Animais de Laboratório: criação e experimentação. Rio de Janeiro, Editora Fiocruz, 2002..

MORTIMER, E.F. Construtivismo, mudança conceitual e ensino de ciências: para onde vamos? Investigações em Ensino de Ciências, v. 1, n. 1, 20-39, 1996.

PEICHOTO, M. E.; TAVARES, F. L.; DEKREY, G. \& MACKESSY, S. P. A comparative study of the effects of venoms of five rear-fanged snake species on the growth of Leishmania major: Identification of a protein with inhibitory activity against the parasite. Toxicon, v. 58, v. 1, 28- 34, 2011.

SANDRIN, M. F. N.; PUORTO, G. \& NARDI, R. Serpentes e acidentes ofídicos: um estudo sobre erros conceituais em livros didáticos. Investigações em Ensino de Ciências, v. 10, n. 3, 281-298, 2006.

SANTOS, W.L.P. \& MORTIMER, E.F. Uma análise de pressupostos teóricos da abordagem CTS (Ciência-Tecnologia-Sociedade) no contexto da educação brasileira. Ensaio - Pesquisa em Educação em Ciências, v.2, n. 1, 2002.

SANTOS, N.S.; COSTA, F.J; DIAS, V. A. \& AMORIM, R. A. A. Educação em saúde: estudo preliminar sobre a utilização de ferramentas alternativas para o ensino de conteúdos relacionados à alimentação em escola básica de Belo Horizonte-MG. III Encontro Nacional de Ensino de Ciências da Saúde e do Ambiente - RJ, Niterói, 2012. 
SILVA, M.A.S.; SOARES, I.R.; ALVES, F.C. \& SANTOS, M.N.B. Utilização de Recursos Didáticos no processo de ensino e aprendizagem de Ciências Naturais em turmas de $8^{\circ}$ e $9^{\circ}$ anos de uma Escola Pública de Teresina no Piauí. VII - Congresso Norte Nordeste de Pesquisa e Inovação, 2012.

SENICIATO, T. \& CAVASSAN, O. Aulas de campo em ambientes naturais e aprendizagem em ciências - um estudo com alunos do ensino fundamental. Ciência e Educação, v. 10, n. 1, 133-147, 2004.

SERPELL, J.A. Factors influencing human attitudes to animals and their welfare. Animal Welfare, v. 13, 145-151, 2004.

VASCONCELOS, S. D.; SOUTO, E. O livro didático de ciências no ensino fundamental - proposta de critérios para análise do conteúdo zoológico. Ciência \& Educação, v. 9, n. 1, 93-104, 2003.

UHMANN, R. I. M.; ZANON, L. B. Diversificação de estratégias de ensino de ciências na reconstrução dialógica da ação/reflexão docente com foco na educação ambiental. Ensaio Pesquisa em Educação em Ciências, v. 15, n. 3, 2013.

ZUG, G.R.; VITT, L.J. \& CALDWELL, J.P. Foraging Ecology and Diets. In Zug, G.R.; Vitt, L.J. \& Caldwell (Ed.), Herpetology: An Introductory Biology of Amphibians and Reptiles. 2ed. Califórnia: Academic Press, 2001. 